\title{
Partnership for the goals to reduce CVD mortality: Rowing in the same direction
}

\author{
João V. Vitola, MD, PhD, MASNC, and Miguel Morita Fernandes-Silva, MD, \\ $\mathrm{MPH}, \mathrm{PhD}^{\mathrm{a}}$ \\ a Quanta, Curitiba, Brazil
}

Received Jul 24, 2019; accepted Jul 25, 2019

doi: $10.1007 / \mathrm{s} 12350-019-01839-0$

See related article, pp. 2048-2054

In 2015, the United Nations (UN) adopted an agenda of 17 Sustainable Development Goals (SDGs) to be achieved by $2030 .{ }^{1}$ Three of these goals are pertinent to our discussion on implementation of imaging technology to evaluate cardiovascular disease (CVD) in special to guide treatment and help reduce mortality due to coronary heart disease (CHD). Goal number 3 deals with good health and well-being; goal number 10 is dedicated to reducing inequalities; and goal number 17 deals with partnership for the goals.

Cardiovascular disease is a fierce enemy. It remains the leading cause of death worldwide, accounting for one-third of all deaths, beating all forms of cancers combined, infectious diseases, and death from injuries. ${ }^{2,3}$ A specific target has been set by the UN to reduce by one-third premature mortality from non-communicable diseases, including CVD, cancer, diabetes mellitus (DM), and chronic respiratory diseases. This is intimately related to the work of UN agency World Health Organization (WHO) but in some extent it also relates to the work being done by the Human Health department, division of nuclear medicine, of the International Atomic Energy Agency (IAEA). In the article of Gutierrez-Villamil et al., ${ }^{4}$ some of the IAEA projects in Latin America and Caribbean region, impacting nuclear cardiology implementation and development, as part of the international effort to help fight against CVD mortality in the region, have been discussed.

Reprint requests: João V. Vitola, MD, PhD, MASNC, Quanta, Curitiba, Brazil; joaovitola@quantamn.com.br

J Nucl Cardiol 2019;26:2055-9.

$1071-3581 / \$ 34.00$

Copyright (c) 2019 American Society of Nuclear Cardiology.

When you hear about an international agency that deals with atomic energy, what comes to your mind? Perhaps something related to atomic bombs, nuclear reactors, energy production, radioprotection, Chernobyl disaster in Ukraine in 1986, or more recently Fukushima Daiichi in Japan in 2011? Well, the IAEA deals with all of these and much more, including the use of atomic energy and technology applied to medicine to help preserve lives! It was created in 1957, as an autonomous organization, with the mandate to promote and help regulate the peaceful use of nuclear energy at the world level. ${ }^{5}$ Although autonomous, the IAEA is within the UN family and reports to its general assembly and security council. The IAEA is localized in a beautiful group of buildings, in the Vienna International Center at the UN headquarters in Austria. If you look from one of its many windows, towards the Danube, you might see groups of people, from different teams, rowing up and down that beautiful river. Let us keep this in mind when we think about teamwork.

\section{WORKING TOWARDS GOOD HEALTH AND WELL-BEING: PREVENTION COUPLED WITH TECHNOLOGY FOR DIAGNOSIS}

Let us go back to the UN SDGs discussed previously and focus on number 3 . To reach good health and well-being in terms of CVD, we must think broadlyprevention coupled with technology when appropriate! Promotion of health and fighting risk factors must occur at the population level, no doubt. We need to prevent $\mathrm{CHD}$ before it develops into advanced stages to the level of putting individuals at high risk of major event such as death. It is unfortunate that development of CHD is usually a silent process and sudden cardiac death is frequently the first sign that the patient had advanced CHD. Of course, this imposes a huge challenge for the medical system-to identify the next potential victim! Once CHD is stablished and advanced, we need more 
than prevention-we need to develop effective strategies to identify high-risk subjects and start aggressive treatment to reduce their chance of dying. We need strategies even if they are still asymptomatic (which is even more challenging). A strategy for investigation is usually easier to be implemented when a red flag is raised by symptoms! Appropriate use of diagnostic imaging technology, for the various clinical scenarios from the sub groups of asymptomatic to the symptomatic, can help us in many ways: to diagnose, to estimate risk, and to guide the best possible treatment, when there is sound scientific evidence proven that a given treatment indeed reduces CHD mortality. ${ }^{6}$ This is where the work being done at the IAEA human health department can help. ${ }^{7}$ Many of the IAEA efforts are to educate professionals on the use of technologies such as nuclear cardiology and coronary computed tomographic angiography. In addition, the IAEA also works to demonstrate which strategies are best fitted to evaluate patients avoiding excessive ionizing radiation. Multimodality diagnostic approaches meaning chosen one best test or a combination of tests in a rationale sequence to decide on the best treatment to manage CHD for a given patient. These modalities may use ionizing radiation but not always, such as the use of exercise treadmill testing, echocardiography, and magnetic resonance imaging. ${ }^{6,8,9}$ This is where a global perspective in multimodality becomes useful.

\section{REDUCING INEQUALITIES: TAKING TECHNOLOGIES TO LMICS AND THE FIGHT AGAINST CVD MORTALITY}

Despite several advances in the last three decades, CVD has proportionally imposed a higher burden to low-and-middle-income countries (LMICs) and some of the poorest regions of the world. While CV mortality remarkably decreased in high-income countries (HICs), it remained either stable or decreased at a much slower rate in LMICs. ${ }^{3}$ This brings an extra burden to countries already economically challenged. Overall, $80 \%$ of the 17.3 million deaths due to CVD every year worldwide occur in LMICs. In addition, the rates of premature CVD (below age 70) remain excessively high in these countries. ${ }^{4,10}$ Reasons for these sociodemographic-related disparities are complex and multifactorial, including exposure to modifiable risk factors, socioeconomic issues, and access to effective healthcare technology and interventions. ${ }^{3,11,12}$

To effectively reduce CV mortality in LMICs, we need to couple prevention with the appropriate use of diagnostic technologies. The IAEA, aligned with SDG number 10 (work towards reducing inequalities), has a special attention to support LMICs in their efforts to implement and use imaging technology, notably those that are more advanced and involve ionizing radiation, such as but not limited to nuclear cardiology. ${ }^{9,13}$ Some of our prior work have demonstrated that the availability of nuclear cardiology technology is very heterogeneous worldwide. Noteworthy, as mentioned before, some of the countries with high CVD mortality rates are coincident with those where diagnostic technology is very limited. The IAEA has been offering support in different ways but mainly through technical cooperation projects with its member states (currently 171 nations are members). The IAEA helps with diffusion of scientific relevant information, education/training, sponsoring fellowships and scientific visits, fostering research in the field, publishing standards and guidance on how to implement them, and partnering with government for implementation of nuclear technology in LMICs. When we observe the top ten countries in the world with the highest CV mortality in 2015, four are in Latin America and the Caribbean (Argentina, Brazil, Cuba, and Mexico). ${ }^{14}$ This by itself deserves a special attention from the UN and its agencies ${ }^{6}$ working with scientific societies in the region to build local capacities to fight CVD at all levels, including the peaceful use of atomic energy to evaluate CVD. Examples of these are demonstrated in the article by Guttierrez-Villamil et al.

Availability of multimodality imaging facilities can significantly change the diagnostic and therapeutic management of CHD. When we say that some of the same countries with high $\mathrm{CV}$ mortality are the same ones with the lowest or inexistent availability of advanced imaging technologies, ${ }^{8,15}$ we are not stating a causal relationship between lack of nuclear cardiology and high CV mortality. This association is much more complex and may reflect an overall challenging environment for socioeconomic development, which includes lower availability of advanced technology in medicine to guide treatment in general. Nevertheless, we may think that the availability of imaging technology, or the lack of it, may be the difference between being able, or not, to provide and guide to the 


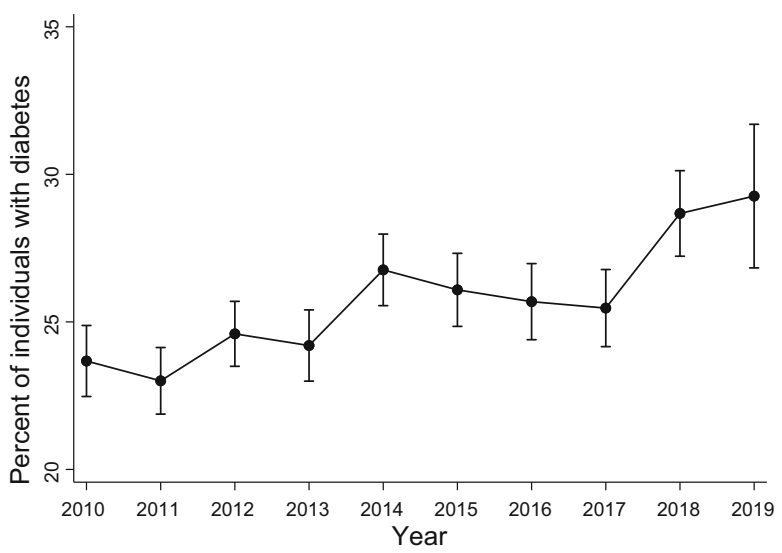

Figure 1. Time trends in the prevalence of diabetes mellitus among 44,589 individuals referred to MPI-SPECT at QUANTA in Curitiba, Brazil from 2010 to 2019. MPI-SPECT, myocardial perfusion imaging with single photon emission computed tomography.

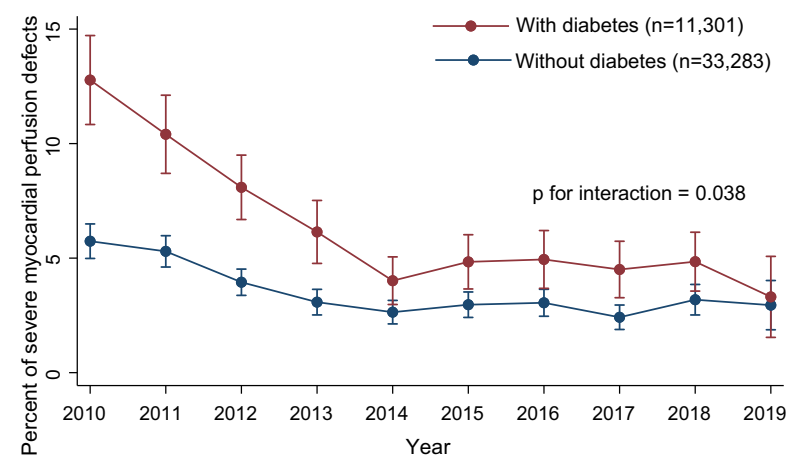

Figure 2. Time trends in percent of individuals with severe myocardial perfusion defects, with and without diabetes mellitus, referred to MPI-SPECT at QUANTA in Curitiba, Brazil from 2010 to 2019. MPI-SPECT, myocardial perfusion imaging with single photon emission computed tomography. *Severe myocardial perfusion defects defined as summed stress score 13 or above. $P$ for interaction less than 0.05 indicates that the rate of decline in the prevalence of severe myocardial perfusion defects differed between individuals with and without diabetes. Observe that, despite severe myocardial perfusion defects being found more frequently in diabetic patients, this difference has progressively decreased over the last decade.

most effective and even cost-effective treatment for patients with CHD. With the growing disparities in CVD burden, this scenario is likely to worsen with lack of investment in the poorest regions; another good reason to focus on SDG number 10 .

\section{PARTNERSHIP FOR THE GOALS AND FUTURE DIRECTIONS}

It is not any given imaging technology that reduces mortality; what reduces mortality is appropriate treatment! Imaging technology provides more information to the clinician that will help him to decide on the best treatment strategy! Nuclear cardiology continues to be useful and higher the prevalence of disease, more important is the role of nuclear to guide management. ${ }^{8}$ The presence or absence of myocardial ischemia in myocardial perfusion imaging with single photon emission computed tomography (MPI-SPECT) translates into different levels of risk. This information helps guide treatment and better allocate expensive medical resources, such as myocardial revascularization. ${ }^{15}$

The scenario of CVD in many LMICs tends to be more challenging in the future related to the increasing prevalence of DM in some regions. The International Diabetes Federation estimates that, in the next three decades, the prevalence of DM will increase $156 \%$ in Africa, $84 \%$ in Asia, and $62 \%$ in Latin America. ${ }^{16}$ These regions will be the most affected in the World. In Brazil, we have in general a good experience with the use of nuclear cardiology to evaluate patients with high risk for developing or who have already developed CHD. At our large nuclear cardiology registry at QUANTA in Curitiba, Brazil, we are observing a growing number of individuals with DM referred to MPI-SPECT studies over the last decade (Figure 1). Interestingly, we are also seeing a decrease in the proportion of individuals with severe myocardial perfusion defects and this has been more striking exactly in the DM population (Figure 2). This is impressive and potentially reflects a better attention and effective management to control this highrisk group of patients (DM) in our region. In parallel, we are observing a progressive decrease in CV mortality, both global and premature ( $<70$ years-old) in the city of Curitiba (Figure 3). This data gives us hope that despite the challenges imposed, including a higher prevalence of important risk factors such as DM, we can apply successful strategies and observe reduction in mortality at the population level.

Partnership for the goals is the 17th, the last of the items on the SDG list and a very important one! In the context of CHD, it means building bridges and teams to work together. Collaboration is a key factor in reducing CV mortality worldwide. In the era of technology, combining primordial prevention with modern diagnostic strategies to best serve patient's interest is one 


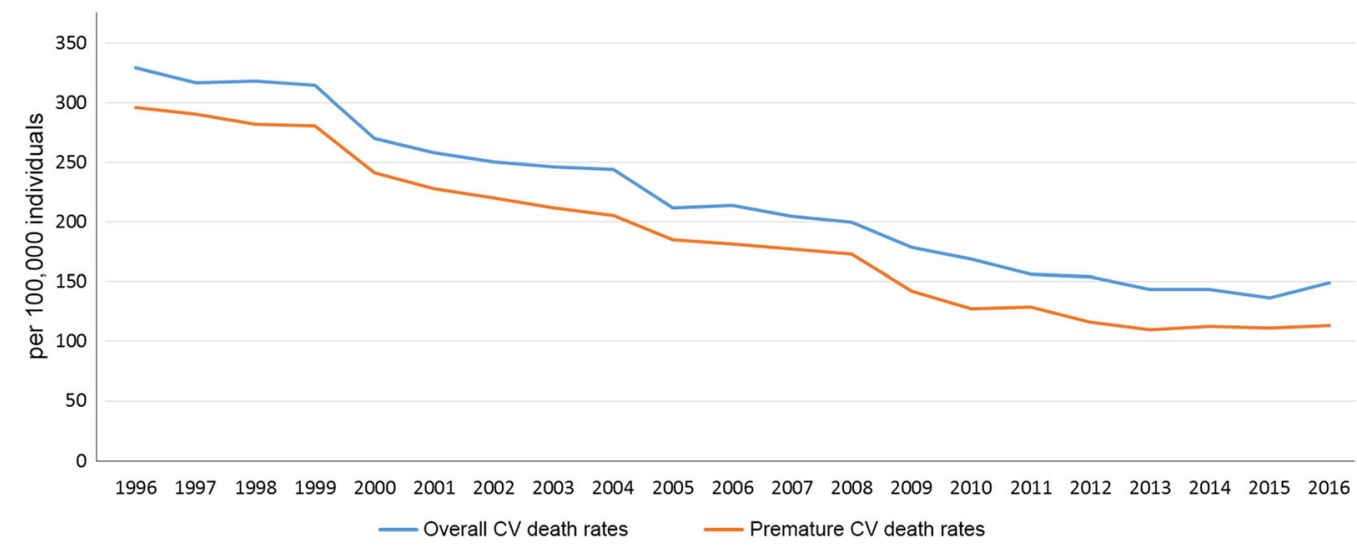

Figure 3. Overall and premature cardiovascular mortality rates per year in City of Curitiba, Brazil. * Graph shows age-standardized rates using a WHO World Standard Population. ${ }^{17}$ Mortality data were obtained from Sistema de Informação em Mortalidade (SIM) database, which contains information from all death certificates in the city of Curitiba. Population data were obtained from 2010 Census Data from the Brazilian Institute of Geography and Statistics database.

important form of partnership. In addition, partnerships among institutions, UN agencies, such as WHO, IAEA, and scientific societies, including but not limited to the World Heart Federation, should be fortified towards better health and well-being of humanity. After all, by working together, rowing on the same direction is the way we can go not only much further but invariably much faster!

\section{Acknowledgements}

The authors acknowledge and thank Curitiba secretary of health Marcia Huçulak, director of epidemiology Alcides Augusto Souto de Oliveira, and Mayor Rafael Greca de Macedo for providing Curitiba cardiovascular mortality data for Figure 3.

\section{Disclosure}

The authors João V. Vitola and Miguel M. FernandesSilva declare that they have no conflicts of interest beyond the fact that both work with investigations in the field of cardiac imaging.

\section{References}

1. United Nations Sustainable Development Goals Knowledge Platform. https://sustainabledevelopment.un.org/. Accessed $18 \mathrm{Jul}$ 2019

2. World Health Organization: The top 10 causes of death. https:// www.who.int/en/news-room/fact-sheets/detail/the-top-10-causes-o f-death. Accessed 18 Jul 2019

3. Roth GA, Johnson C, Abajobir A, Abd-Allah F, Abera SF, Abyu G, et al. Global, regional, and National Burden of cardiovascular diseases for 10 causes, 1990 to 2015. J Am Coll Cardiol 2017;70(1):1-25.

4. Gutierrez-Villamil C, Peix A, Orellana P, Berrocal I, Ramirez R, Estrada-Lobato E, et al. Impact of International Atomic Energy Agency support to the development of nuclear cardiology in lowand middle-income countries: case of Latin America and the Caribbean. J Nucl Cardiol 2019. https://doi.org/10.1007/s12350019-01805-w.

5. International Atomic Energy Agency website. https://www.iaea. org. Accessed 18 Jul 2019

6. Vitola JV. A need to reduce premature CV mortality in the developing world: How could appropriate use of non-invasive imaging help? J Nucl Cardiol 2019;26(3):975-85.

7. Vitola JV, Shaw LJ, Allam AH, Orellana P, Peix A, Ellmann A, et al. Assessing the need for nuclear cardiology and other advanced cardiac imaging modalities in the developing world. $\mathbf{J}$ Nucl Cardiol 2009;16:956-61.

8. Vitola JV, Cerci R. Mexico-city does not look like Beverly-Hills: A multimodality and cardiac imager perspective! J Nucl Cardiol 2019. https://doi.org/10.1007/s12350-019-01806-9.

9. International Atomic Energy Agency. Nuclear cardiology: Its role in cost effective care. Vienna: International Atomic Energy Agency. Human Health Series; 2012. https://www.iaea.org/publica tions/8601/nuclear-cardiology-its-role-in-cost-effective-care

10. Roth GA, Huffman MD, Moran AE, Feigin V, Mensah GA, Naghavi M, et al. Global and regional patterns in cardiovascular mortality from 1990 to 2013. Circulation 2015;132:1667-78.

11. Schultz WM, Kelli HM, Lisko JC, Varghese T, Shen J, Sandesara $\mathrm{P}$, et al. Socioeconomic status and cardiovascular outcomes: Challenges and interventions. Circulation 2018;137(20):2166-78.

12. Enard KR, Hauptman PJ. Heart failure, shared decision making, and social determinants of health: An upstream perspective. JAMA Cardiol 2019. https://doi.org/10.1001/jamacardio.2019. 2467.

13. IAEA. Nuclear cardiology: Guidance on the implementation of SPECT myocardial perfusion imaging. IAEA Human Health Serial. 2016

14. Mozaffarian D, Benjamin EJ, Go AS, Arnett DK, Blaha MJ, Cushman M, et al. Heart disease and stroke statistics: 2016 update. Circulation 2015;133(4):e38-48. 
15. Vitola JV. Nuclear cardiology and CVD in the developing world: Are we applying our scarce resources appropriately? Why is our mortality rate so high? J Nucl Cardiol 2016;23(5):1166-70.

16. International Diabetes Federation Diabetes Atlas, 8th edition. https://www.diabetesatlas.org/resources/2017-atlas.html
17. Ahmad OB, Boschi-Pinto C, Lopez Christopher AD, Murray JL, Lozano R, Inoue M. Age standardization of rates: A new who standard. World Health Organization; 2001.

Publisher's Note Springer Nature remains neutral with regard to jurisdictional claims in published maps and institutional affiliations. 